\title{
Effect of Different Degumming Processes and Some Nontraditional Neutralizing Agent on Refining of RBO
}

\author{
Bijay Krishna De* and J.D. Patel \\ Department of Industrial Chemistry, Division of Oils, Fats \& Waxes, Institute of Science \& Technology for Advanced Studies \& Research \\ (ISTAR) (Vallabh Vidyanagar-388 120, Anand, Gujarat, INDIA)
}

\begin{abstract}
The present investigation aimed at finding out the effect of different degumming processes and on the use of some nontraditional alkaline material for refining of rice bran oil. Attempt was made to treat crude rice bran oil with $\mathrm{H}_{2} \mathrm{O}$, and $\mathrm{H}_{3} \mathrm{PO}_{4}$ for degumming followed by with alum or $\mathrm{H}_{2} \mathrm{O}$ for dewaxing. After removal of the gums and waxes the oil was neutralized with commonly used $\mathrm{NaOH}$, and some nontraditional neutralizing agents like $\mathrm{Na}_{2} \mathrm{CO}_{3}$ and $\mathrm{NaHCO}_{3}$. Finally the oil was bleached traditionally using earth and charcoal and deodorized. The RBD oil was characterized by determining their color, peroxide value, content of unsaponifiable matter, and free fatty acids. Among the different processes tried degumming with $0.2 \%$, w/w, $\mathrm{H}_{3} \mathrm{PO}_{4}$ followed by dewaxing with $2.0 \%$, w/w, $\mathrm{H}_{2} \mathrm{O}$; bleaching with tonsil earth $(1.5 \%, \mathrm{w} / \mathrm{w})$ and charcoal $(0.5 \%, \mathrm{w} / \mathrm{w})$ and finally deodorization at $220^{\circ} \mathrm{C}$ temperature and $2-4 \mathrm{~mm}$ $\mathrm{Hg}$ pressure resulted best quality oil in terms of the measured parameters. The characteristics of refined rice bran oil could be as content of FFA and UM $0.2(\%, w / w), 2.6(\%, w / w)$ respectively; color 10.9Y, 2.0R (in $2.54 \mathrm{~cm}$ Lovibond Tintometer cell); PV 3.3 (meq/kg). The oil yield is 78-85 \% (by weight).
\end{abstract}

Key words: degumming, rice bran oil, refining

\section{INTRODUCTION}

Refined rice bran oil (Oryza sativa) is an excellent salad and frying oil with high oxidative stability ${ }^{1)}$ resulting from its high level of tocopherols, tocotrienols and oryzanols (ferulic acid esters of sterols and triterpene alcohols, ferulic acid is 3-methoxy 4-hydroxycinnamic acid). Rice bran oil has remarkable cholesterol lowering property ${ }^{2)}$ in comparison with other cooking oils which is primarily due to its content of higher levels of non-triglyceride components, most of which are removed during further refining processes. Although the provides a number of nutritional benefits one of the major problems associated with rice bran oil is its higher content of free fatty acids, monoglycerides and diglycerides caused by enzymatic hydrolysis of oil within the bran itself. The phospholipids predominantly include phosphatidyl choline, phosphatidyl ethanolamine, and phosphatidyl inositol. The wax content of rice bran oil can be somewhat variable, depending upon cultivar and processing parameters. There are some problems like dark color, haziness, higher amounts of unsaponifiables and foaming during frying that create set backs for its marketing as an edible oil. It is considered the most difficult oil to refine meeting edible oil specifications in terms of its physical and chemical characteristics that govern the marketability of the product. Attempts have been made to solve refining problems ${ }^{3-6)}$ of crude rice bran oil (CRBO). Bhattacharyya and Bhattacharyya ${ }^{3)}$ have investigated the degumming of high FFA containing $\mathrm{RBO}$ using $\mathrm{H}_{3} \mathrm{PO}_{4}$, $\mathrm{H}_{2} \mathrm{SO}_{4}$, citric acid or their mixtures. Hartman and Dos Reis ${ }^{4)}$ have studied and shown that higher refining loss of $\mathrm{RBO}$ is due to the content of higher level of hydroxyl compounds. Long back Mattikow had studied the refining of different oils using sodium carbonate ${ }^{5}$. A new degumming protocol has been developed ${ }^{6)}$ which employs electrolyte solutions to remove nonhydratable gums from soybean, rice bran and mustard oils. De and Bhattacharyya ${ }^{7}$ have

\footnotetext{
*Correspondence to: Bijay Krishna De, Reader in Industrial Chemistry, PG Department of Industrial Chemistry,Shee M\&N Virani Science College, Kalavad Road, Rajkot-30005, Gujarat, INDIA

E-mail: bijay_de@yahoo.co.in
}

Accepted November 12, 2009 (recieved for review June 2, 2009)

Journal of Oleo Science ISSN 1345-8957 print / ISSN 1347-3352 online

http://www.jstage.jst.go.jp/browse/jos/ 
proposed a single step degumming-dewaxing process using $\mathrm{H}_{2} \mathrm{O}$ and shown that after physical refining good quality oil can be obtained in terms of color. Different investigators have concluded that pretreatment of RBO plays a key role in the quality of final product especially of the color. Therefore, attempts have also been made for improving the technology of degumming and dewaxing.

Membrane separation has been proposed as an alternative to the conventional procedure (water degumming) but problems related to the stability of polymeric membrane in contact with the oil extraction solvent (n-hexane) have delayed the application of this technique at industrial scale. In comparison, inorganic membranes are more stable chemically and can tolerate higher temperatures than polymeric based membranes, making them a promising candidate for this application ${ }^{8}$. A number of investigators have studied physical separation of gums using polymeric membranes ${ }^{9-14}$. Degumming using enzymes has drawn attention during the last two decades ${ }^{15-17)}$. The literature shows that through enzymatic process almost complete separation of gums is possible with lowering the chances of color degradation during physical refining or deodorization.

Although a bit of work has been pursued on the pretreatment of rice bran oil with the objective of complete removal of undesired (from consumers point of view) minor constituent (gums and waxes) no comparative data is available on the efficiency of commonly practiced degumming and dewaxing processes. Therefore degumming and dewaxing of a high acid containing crude rice bran oil sample is studied using different routes. The degummed dewaxed oil thus obtained was subjected to neutralization with $\mathrm{NaOH}, \mathrm{Na}_{2} \mathrm{CO}_{3}, \mathrm{NaHCO}_{3}$ to compare the different pretreatment as well as refining processes on rice bran oil.

\section{MATERIALS AND METHODS}

\subsection{Materials}

Crude rice bran oil samples were obtained from Shree Ambica Oil Cake \& Meal Ltd. (Khatrej, Mahemdabad, Gujarat, India). Sodium hydroxide, Sodium carbonate, Sodium bicarbonate, Phosphoric Acid and Alum were purchased from S.D. Fine-Chem, Boiser, Thane, Maharastra, India.

\subsection{Methods}

2.2.1 Degumming and dewaxing of Crude Rice bran oil

Crude oil (ca. $50 \mathrm{~g}$ ) was taken in a beaker (Cap. $250 \mathrm{~mL}$ ) which was placed on a constant temperature water bath maintained at $70^{\circ} \mathrm{C}$. The beaker containing the oil was fitted with a mechanical stirrer (Remi Make, Mumbai) and the oil was stirred. When the desired temperature was attained definite amount of degumming agent (e.g. water, $\mathrm{H}_{3} \mathrm{PO}_{4}$, or a combination of these) was added. The stirring was continued for $30 \mathrm{~min}$ and then the oil was centrifuged (at 12,000 rpm) for $15 \mathrm{~min}$ if the degumming was carried out separately. The treated oil was then cooled to a temper-

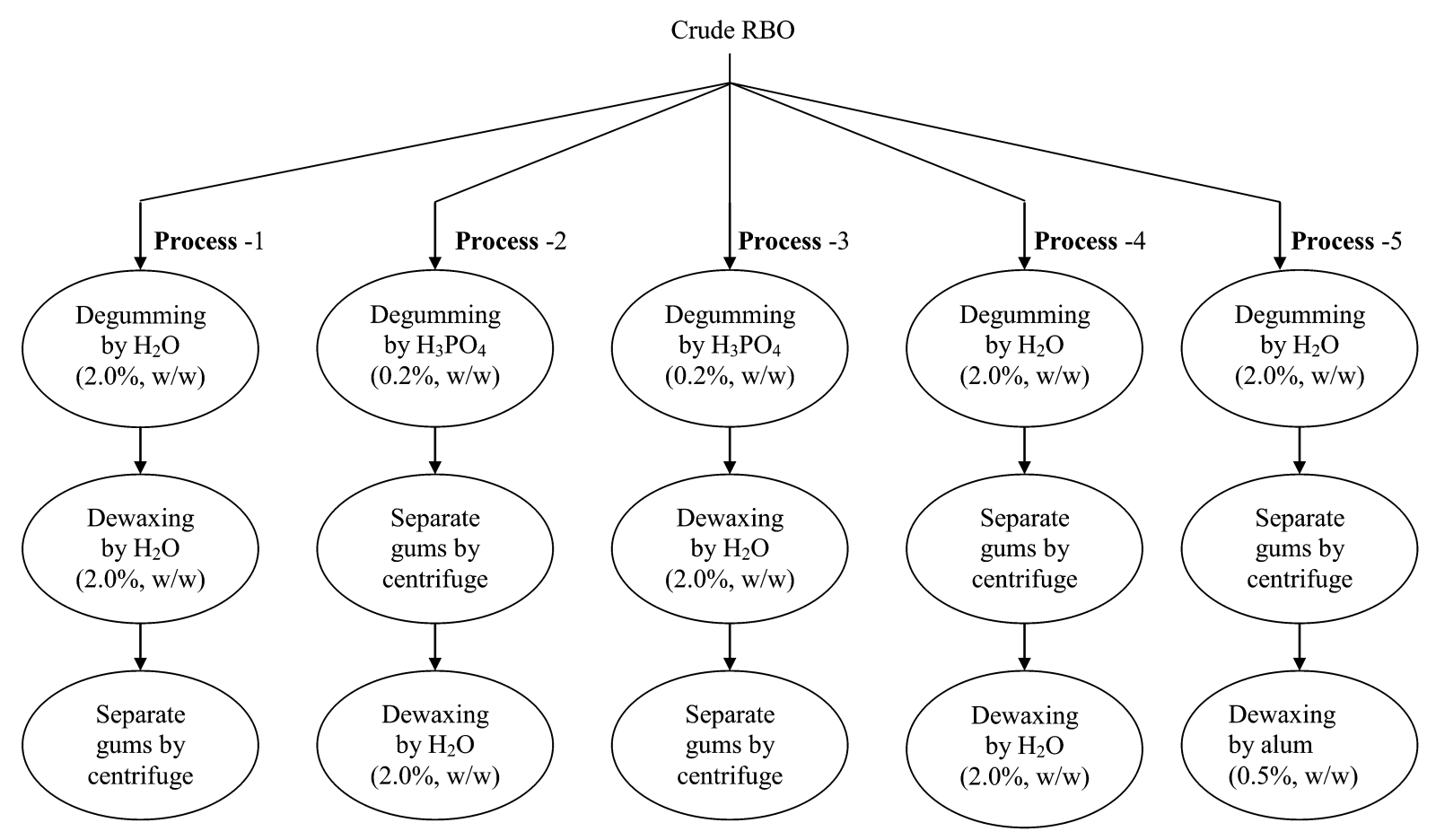

Fig.1 Schematic Diagram of Degumming-Dewaxing Steps of RBO. 
ature of $8-10^{\circ} \mathrm{C}$ and a definite quantity of either water or alum was added. The temperature was maintained and the stirring was continued for another 30 minutes. Finally the oil was centrifuged for $15 \mathrm{~min}$ at 12,000 rpm to separate the wax. A detailed diagram showing the different routes followed in the present investigation for degumming and dewaxing is given in Fig. 1.

2.2.2 Neutralization of degummed-dewaxed rice bran oil

Degummed-Dewaxed oil so obtained was taken in a beaker $(250 \mathrm{~mL})$. Oil was stirred with a mechanical stirrer at $70^{\circ} \mathrm{C}$ and calculated amount $(10 \%, w / w$, excess over the stoichiometric quantity) of alkali (as 15\% w/v, solution in $\mathrm{H}_{2} \mathrm{O}$ ) was added slowly. Stirring was continued for $30 \mathrm{~min}$ and centrifuged at $12,000 \mathrm{rpm}$ in a Remi (Mumbai) make (Model: C24). The separated soap was removed and the oil was washed with hot distilled water till the oil becomes completely free from soap as tested with phenolphthalein indicator. The oil was then dried on water bath (maintained at $90^{\circ} \mathrm{C}$ ) under vacuum (150 $\mathrm{mmHg}$ pressure). Neutralization of $\mathrm{RBO}$ was investigated using different neutralizing agents like $\mathrm{NaOH}, \mathrm{Na}_{2} \mathrm{CO}_{3}, \mathrm{NaHCO}_{3}$ following the same procedure as mentioned above. Finally the neutralized oil was subjected to bleaching.

2.2.3 Bleaching of neutralized rice bran oil

Neutralized oil was bleached according to standard method $^{18)}$. Oil was taken in a flat bottom standard joint (B24) flask (Cap. $100 \mathrm{~mL}$ ) made of Borosil glass and heated to (on water bath) $90^{\circ} \mathrm{C}$ with stirring under low pressure $(10$ $\mathrm{mmHg})$. Then Tonsil earth (1.5\%, w/w) and activated charcoal $(0.5 \%, \mathrm{w} / \mathrm{w})$ were added with constant stirring using a Teflon coated magnetic stir bar. After stirring for $30 \mathrm{~min}$, oil was filtered through filter paper (Whatman No.41) under vacuum.
2.2.4 Deodorization of bleached rice bran oil

Bleached Rice bran Oil was deodorized in batch laboratory deodorizer ${ }^{19)}$ (made of Borosil glass) at $220^{\circ} \mathrm{C}$ under $2-4$ $\mathrm{mmHg}$ pressure. The deodorizer consists of a 3-necked flask where each of the 3 necks was connected with steam injector, thermometer pocket with a thermometer and vacuum system respectively. Deodorization of each sample was carried out for $1 \mathrm{~h}$.

To characterize the crude and refined oil content of FFA, unsaponifiables matter; color and peroxide value were determined according to the standard IUPAC methods ${ }^{20)}$. All the results presented in tables are the arithmetic mean of triplicate set of experiments.

\section{RESULTS AND DISCUSSION}

The physicochemical properties of crude rice bran oil used this present investigation and those after degumming and dewaxing are shown in Table 1. The color (62.2Y, 6.3R in Lovibond scale using $1 / 2$ inch cell), content of free fatty acid $(8.4 \%, \mathrm{w} / \mathrm{w})$ and peroxide value $(28.5 \mathrm{meq} / \mathrm{kg})$ indicate the quality of the oil; whereas, unsaponifiable matter $(3.2 \%$, $\mathrm{w} / \mathrm{w})$, total gum and wax content $(3.30 \%, \mathrm{w} / \mathrm{w})$, phosphorus content $(300 \mu \mathrm{g} / \mathrm{g})$ shows the authenticity of the oil sample used for the investigation. Degummed dewaxed oil samples were characterized by determination of color value (Lovibond $1.27 \mathrm{~cm}$ cell), total gum \& wax content $(\%, \mathrm{w} / \mathrm{w})$ and phosphorus content $(\mathrm{mg} / \mathrm{kg})$. Color of the oils obtained varied from 50.0Y, 5.1R to 56.1Y, 5.1R and total gums and wax content varied from 0.53 to 1.18 (\%, w/w). Phosphorus content of oil degummed by different routes is found to be in between $95-100 \mathrm{mg} / \mathrm{kg}$. Considering the residual phospho-

Table 1 Characteristics of Crude and Degummed-Dewaxed Rice Bran Oil.

\begin{tabular}{|l|l|c|c|c|c|c|c|}
\hline \multirow{2}{*}{$\begin{array}{c}\text { Sr. } \\
\text { No. }\end{array}$} & \multirow{2}{*}{ Characteristics } & Crude Oil & \multicolumn{5}{|l|}{ Characteristics of Degummed-Dewaxed RBO } \\
\cline { 4 - 8 } & & Process-1 & Process-2 & Process-3 & Process-4 & Process-5 \\
\hline 1 & $\begin{array}{l}\text { Free Fatty acids } \\
(\%, \mathrm{w} / \mathrm{w})\end{array}$ & 008.40 & -- & -- & -- & -- & -- \\
\hline 2 & $\begin{array}{l}\text { Unsaponifiable } \\
\text { Matter (\%,w/w) }\end{array}$ & 003.20 & -- & -- & -- & -- & -- \\
\hline 3 & $\begin{array}{l}\text { Peroxide Value } \\
\text { (meq./kg) }\end{array}$ & 028.50 & -- & -- & -- & -- & -- \\
\hline 4 & $\begin{array}{l}\text { Color (Lovibond } \\
1 / 2 " c e l l)\end{array}$ & $62.2 \mathrm{Y}$, & $55.2 \mathrm{Y}$, & $56.0 \mathrm{Y}$, & $50.0 \mathrm{Y}$ & $56.2 \mathrm{Y}$, & $56.1 \mathrm{Y}$, \\
\hline 5 & $\begin{array}{l}\text { Phosphorus } \\
\text { content (mg/kg) }\end{array}$ & 310.00 & 95 & 80 & 97 & 100 & 100 \\
\hline 6 & $\begin{array}{l}\text { Total Gum \& } \\
\text { Wax (\%, } / \mathrm{R} / \mathrm{w})\end{array}$ & 003.30 & 0.54 & 1.18 & 0.53 & 0.67 & 0.77 \\
\hline
\end{tabular}


B.K. De and J.D. Patel

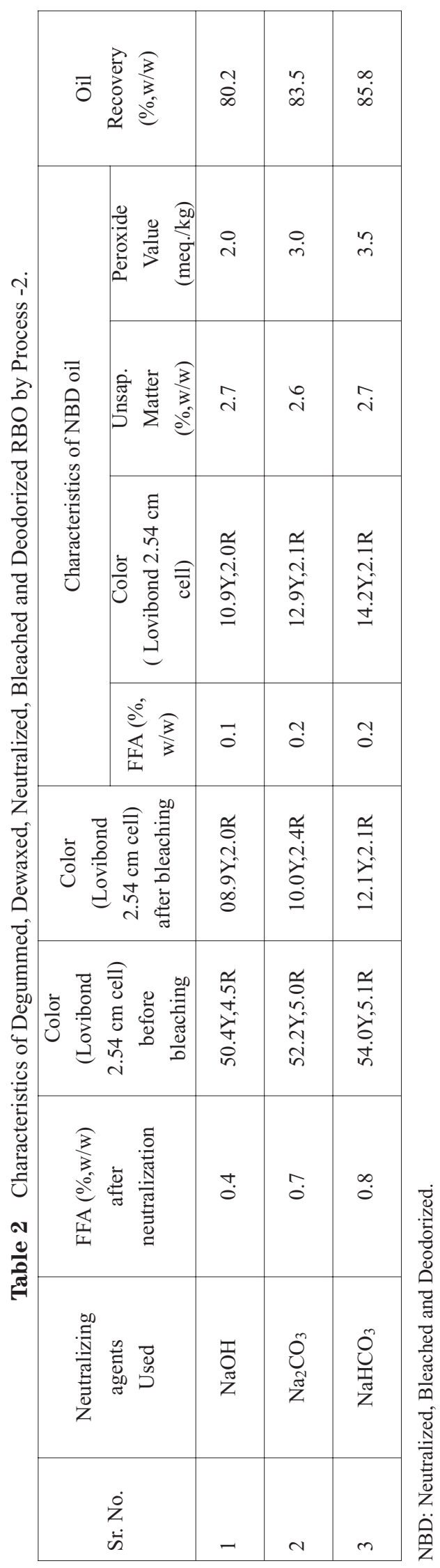


rous content in the oil Process-2 (after treatment $\mathrm{P}$ content is $80 \mathrm{mg} / \mathrm{kg}$ ) is considered to be the best.

Rice bran oil that was obtained through pretreatment Process-2 (refer to Table 2) was refined using three different alkaline neutralizing agents like $\mathrm{NaOH}, \mathrm{Na}_{2} \mathrm{CO}_{3}$ and $\mathrm{NaHCO}_{3}$. After neutralization the FFA content was found to be between $0.4-0.8(\%, \mathrm{w} / \mathrm{w})$ and color values decreased slightly to a level of 50.4Y, 4.5R to 54.0Y, 5.1R. After bleaching with Tonsil earth optimum the color decreased drastically (as expected) 8.9Y, 2.0R to12.1Y, 2.1R. However after deodorization slight darkening of color took place. The results show that after complete refining NBD oil obtained has acceptable physicochemical characteristics: FFA (0.1$0.2 \%, \mathrm{w} / \mathrm{w})$; color (10.9Y, 2.0R to 14.2Y, 2.1R); PV (2.0 to 3.5 $\mathrm{meq} / \mathrm{kg}$ ) and UM content (2.66 to $2.72 \%, \mathrm{w} / \mathrm{w})$. The oil yield is found to be $80.2-85.8 \%$ (by weight).

The study was started with the objective of investigating the effect of different pretreatment processes on the quality of refined rice bran oil. Not only that, it was also aimed to find out the effect of some nontraditional neutralizing agent like $\mathrm{Na}_{2} \mathrm{CO}_{3}$ and $\mathrm{NaHCO}_{3}$ on the quality of refined rice bran oil as well as recovery of oil after complete refining. Irrespective of the five different pretreatment processes followed it is observed that better quality of refined oil is obtained through neutralization with $\mathrm{NaOH}$, although the same resulted in lower recovery of oil. In turn neutralization with $\mathrm{NaHCO}_{3}$ resulted in highest recovery of oil, and $\mathrm{Na}_{2} \mathrm{CO}_{3}$ gave intermediate recovery. This may be due to the highest alkalinity of $\mathrm{NaOH}$ followed by $\mathrm{Na}_{2} \mathrm{CO}_{3}$ and $\mathrm{NaHCO}_{3}$. Higher alkalinity leads to formation of stronger emulsion yielding lesser quantity of oil. It is also found that among the three different neutralizing agents used the color reduction power of $\mathrm{NaOH}$ is the highest and the oil so obtained is best in quality..

\section{References}

1. Gunstone, F.D. Composition and properties of edible oils in Edible Oil Processing (Hamm, W.; Hamilton, R.J. ed.). The Oily Press. Bridgewater, England (2000).

2. Gunstone, F.D. Sources, composition, properties and uses in Chemistry of Oils and Fats. Blackwell Publishing Ltd. CRC Press. Oxford, UK (2004).

3. Bhattacharya, A.C.; Bhattacharya, D.K. Refining of high FFA rice bran oil by mixed solvent-alkali neutralization process. J. Oil Technol. Assocn. India 17, 3132 (1985).

4. Hartman, L.; Dos Reis, M.I.J. A study of rice bran oil refining. J. Am. Oil Chem. Soc. 53, 149-151 (1976).

5. Mattikow, M. Developments in the refining of oils with sodium carbonate. J. Am. Oil Chem. 6, 200-203 (1948).

6. Nasirullah, Physical refining: Electrolyte degumming of nonhydratable gums from selected vegetable oils. $J$. Food Lipids 12, 103-111 (2005).

7. De, B.K.; Bhattacharyya, D.K. Physical refining of rice bran oil in relation to degumming and dewaxing. $J$. Am. Oil Chem. Soc. 75, 1683-1686 (1998).

8. Marenchino, R.; Pagliero C.; Mattea M. Vegetable oil degumming using inorganic membranes. Desalination 200, 562-564 (2006).

9. Zhang, S.Q. Kutowy, O.; Kumar, A. Application of ultrafiltration membranes in refining of crude vegetable oils. in Proceedings of the $8^{\text {th }}$ Annual Meeting of North American Membrane Society. Ottawa, Canada. p.95 (1996).

10. Alicieo, T.V.R.; Mendes, E.S.; Pereira, N.C.; Lima, O.C.M. Membrane ultrafiltration of crude soybean oil. Desalination 148, 99-102 (2002).

11. Hafidi, A.; Pioch D.; Ajana, H. Membrane-based simultaneous degumming and deacidification of vegetable oils. Innov. Food Sci. Eng. Technol. 6, 203-212 (2005).

12. Moura, de, J.L.M.N.; Gonçalves, L.A.G.; Petrus, J.C.C.; Viotto, L.A. Degumming of vegetable oil by nicroporous membrane. J. Food Eng. 70, 473-478 (2005).

13. Koris, A.; Vatai, Gy. Dry degumming of vegetable oils by membrane filtration. Desalination 148, 149-153 (2002).

14. Subramanian, R.; Nakajima, M. Membrane degumming of crude soybean and rapeseed oils. J. Am. Oil Chem. Soc. 74, 971-975 (1997).

15. Henning, B.; Rudolf, B.; Joerg S. Process for enzymatically degumming vegetable oil. US Pat. 5558781 (1996).

16. Fridolin, L.; Hermann, P.; Bruno, S.; Hans, O. Vegetable oil enzymatic degumming process by means of Aspergillus phospholipase. US Pat. 6001640 (1999).

17. Bo, Y.; Yong-Hua W.; Ji-Guo Y. Optimization of enzymatic degumming process for rapeseed Oil. J. Am. Oil Chem. Soc. 83, 653-658 (2006).

18. Anderson, A.J.C. Refining of Oils and Fats for Edible Purposes (Williams, P.N. ed.). $2^{\text {nd }}$ ed. Pargamon Press. Oxford, London (1962).

19. De, B.K. Ph.D. thesis. University of Calcutta (1999).

20. IUPAC Standard Methods for the Analysis of Oils, Fats and Derivatives. $7^{\text {th }}$ ed. Blackwell Scientific Publications. Oxford, UK. Methods 2.201, 2.202, 2.205, 2.401, 2.501 (1987). 